\title{
Presence Equation: An Investigation Into Cognitive Factors Underlying Presence
}

\author{
Corina Sas and Gregory M.P O’Hare \\ University College Dublin
}

\begin{abstract}
The relationship between presence and cognitive factors such as absorption, creative imagination, empathy, willingness to experience presence and cognitive style was investigated. Presence was defined, opcrationalized and measured using a questionnaire devised by us. Absorption and creative imagination were measured using questionnaires developed in the area of hypnosis. Results indicated significant correlations between presence and each cognitive factor. They showed that persons who are highly absorbed, more creative, more empathic or more willing to get immersed experienced a greater sense of presence. Regression analysis led to presence equation, which could be used to predict presence based on investigated cognitive factors. Findings are congruent with user's characteristics presented by presence literature and support the position that individual differences are important for the study of presence.
\end{abstract}

Psychological approaches to the study of presence are scarce, and those with experimental support are even more limited. This work is an attempt to highlight the human factors involved which may lead to a better understanding of individual differences in relation to the experience of presence.

Study objectives consisted in (a) defining and operationalizing presence, (b) identifying a set of cognitive factors determinant for presence and (c) identifying a presence equation which describes a relationship that holds between these factors.

We investigated the relationship between each of the following cognitive factors: absorption, creative imagination, empathy, willingness to experience presence, cognitive style, and the sense of presence experienced by the users. The results enable us to describe a presence equation, employing a deeper and more thorough approach to the psychology of presence.

\section{Defining Presence}

Even though the idea of telepresence was anticipated by Robert Heinlein (1950) in his novel Waldo, the term was coined by Marvin Minsky (1980) and denotes a sense of being physically present at a remote world which is mediated by the system interface. In a widely accepted assertion, Sheridan (1992) and Schloerb and Sheridan (1995) described presence as a sense of being physically present at the remote site. As Loomis (1992) pointed out presence is a basic state of consciousness, consisting of attribution of sensation to some distal stimuli, or more broadly to some environment. Underlying the failure of mediation awareness, I combard and Ditton (1997) conceptually delimited presence as "the perceptual illusion of non-mediation". Slater and Usoh (1993) described presence as "suspension of disbelief" experienced by users of being in a remote world and not in the physical one.

Building upon the aforementioned presence definitions, we were interested in identifying, according with traditional definition theory, their genus and differentia. Thus, the concepts used for delineating the genus were state of consciousness (Loomis, 1992), psychological state (L combard, 2002), subjective experience (Heeter, 1992), subjective perception (I combard, 2000), sense (Minsky, 1980; Sheridan, 1992) and illusion (Lombard \& Ditton, 1997). Considering presence merely as a sense is, in our opinion, unnecessarily restrictive. At the same time however, the state of consciousness enlarges the boundaries of genus more than necessary, since everything that occurs in the internal world, the subjective world of inner thoughts (Jung, 1971), represents states of consciousness.

While we have identified quite a large array of terms delineating genus, the distinguishing features which are supposed to differentiate sense of presence from other psychological phenomena, were better expressed. The unanimously accepted construct of being there is the core aspect of presence, which occurs within one's consciousness. We consider that in this case we should talk about a shift of focus of consciousness (Lauria, Nov. 2000) from the local environment to a remote one, shift which occurs insidiously.

In seeking a closer juxtaposition to the theoretical framework underlying it, we define presence as follows: Presence is a psychological phenomenon, through which one's cognitive processes are oriented toward another world, either technologically mediated or imaginary, to such an extent that he or she experiences mentally the state of being (there), similar to one in the physical reality, together with an imperceptible shifting of focus of consciousness to the proximal stimulus located in that other world.

\section{Presence Operationalization}

According to Revonsuo (1996) immersion and sense of presence are fundamental aspects of the high level structure of the consciousness experience. Farthing (1992) considered consciousness as "a subjective state of being currently aware of something, either within oneself or outside of oneself", 
(p. 6). According to him, primary consciousness consists of direct experience and spontaneous response to it, while reflective consciousness focuses on conscious experience per se, which becomes the object of one's thoughts.

Kim and Biocca's (1997) findings considered presence as a two-dimensional construct consisting of being there and not being here. Drawing a parallel with Gerrig's work in understanding the meaning of being transported by a narrative (Gerrig, 1993), Kim and Biocca associated these dimensions with the the arrival in the virtual environment and the departure from the physical environment, respectively. Both these two dimensions facilitate access to the content of primary consciousness. In order to address also the content of reflective consciousness, we consider it as an additional dimension (e.g. awareness of being there).

To measure any construct one should establish a connection between it and the physical reality. Translating a construct into its manifestation is the process of operationalization (Trochim, 2000). It consists of identifying the conceptual dimensions, finding whithin each dimension the associated measurable variables and choosing for each variable its actual measures in terms of indicators. Based on these observations, we identified presence variables associated with each dimension as summarized in Table 1. For example, the variable acting there, whithin the dimension Being there was tapped by two items of the questionnaire: a) To what extent did you really feel yourself navigating within another world, and b) To what extent did you feel as the results of your interactions with the remote environment can "touch" you.

Table 1

Presence Operationalization

\begin{tabular}{clll}
\hline Dimen. & \multicolumn{2}{c}{ Primary consciousness } & Reflective \\
& Being there & Not being here & conscious. \\
\hline Variables & Perceiving & Not perceiving & Awareness \\
& Recalling & Not recalling & of oneself \\
& Imagining & Self perception & Awareness \\
& Thinking & Returning exper. & of outside \\
& Affective proc. & Affective proc. & \\
& Willingness & Refusal to exper. & \\
& Acting there & Not acting & \\
Attentional res. & Attentional res. & \\
\hline
\end{tabular}

\section{Technological Factors}

The determinant factors affecting presence can be grouped into technological factors which consider the system and its characteristics, and human factors referring to users' cognitive and personality aspects (Lombard \& Ditton, 1997; Lessiter, Keogh, \& Davidoff, 2000). A large amount of work has been carried out in the area of technological factors affecting presence. Lombard and Ditton (1997) provided a detailed presentation in this direction. Part of these factors are summarized below: visual display characteristics such as image quality, image size, viewing distance, visual angle, mo- tion, color, dimensionality, camera techniques; aural presentation characteristics like frequency range, dynamic range, signal to noise ratio, high quality audio or dimensionality such as 3-D sound. As stimuli for other senses, Lombard and Ditton (1997) referred to olfactory output, body movement, tactile stimuli, and force feedback. Media user's characteristics were often mentioned as carrying a particular impact upon the experienced level of sense of presence. However, there is little empirical research supporting this.

\section{Human Factors}

Psotka and Davison (1994) considered two categories of factors determinant of immersion, such as susceptibility to immersion and quality of immersion. The first set refers to human factors with an emphasis on cognitive aspects such as imagination, vivid imagery, concentration, attention and self-control, while the second set is primarily concerned with technological factors like affordances of virtual reality(VR) environment, distractions from the real world or indeed physiological effects.

As Kaber, Draper and Usher (2002) pointed out, the personality traits discussed in the VR literature seem to be predominantly mentioned in the context of presence experienced within the virtual environment. These factors were primarily referred to as immersive tendencies and attention. They cover an entire set of users' characteristics such as suggestibility of immersion, tendency to daydreaming, becoming lost in novels, concentration and robustness to distracting events. *** Personality aspects (Slater \& Usoh, 1993; Heeter, 1992) have also been identified as relevant when one experiences presence.*** As we will see in the following subsections, empathy, absorption and creative imagination specifically target these factors. *** traits and tranzitory***

Empathy. Empathy is probably the most frequently mentioned cognitive aspect, which may affect presence (Lombard, 2002). I combard and Ditton (1997) suggested that intensity and polarity of emotions experienced by users during mediated activities could prove significance to presence, even though no empirical study had yet demonstrated it. Davis (1994) identified empathy with a set of constructs associated with the responses of one individual to the experience of another. It involves the ability to engage in the cognitive process of adopting another's psychological point of view, together with the capacity to experience affective reactions to the observed experience of others. In order to develop such capacities and exhibit empathic behavior, one should be able to assume perceptual, cognitive and affective roles.

Theoretical perspective in the psychology of hypnosis offers insights for the study of presence. The work carried out within this field, provides both valuable theoretical issues, and valid instruments, which can be harnessed to investigate personality traits related to presence.

Absorption. Lombard and Ditton (1992) suggested absorption as another possible factor influencing presence. They mentioned Quarrick's (1989) work, who indicated that 
during absorption, sense of self and time fades as the person merges with a fascinating stimulus.

The first researcher who discovered the personality aspects related to hypnotizability was Josephine Hilgard (1970). Through an extensive interview study, she identified that highly hypnotizable individuals tend to present a high level of imaginative involvement in domains such as reading, drama, religion, affective arousal, adventures and artistic creativity. Based upon Hilgard's findings, Tellegen (1982) and Tellegen and Atkinson (1974) developed the TAS in order to measure the extent to which people become involved in everyday events or the tendency to totally immerse oneself with the attentional objects.

The absorption construct elaborated by Tellegen (1981) is defined as a state of "openness to experiencing, in the sense of readiness to undergo whatever experiential events, sensory or imaginal, that may occur, with a tendency to dwell on, rather than go beyond, the experiences themselves and the objects they represent" (p. 222). Attention described in absorption terms "is a total attention, involving a full commitment of available perceptual, motoric, imaginative and ideational resources to a unified representation of the attentional object" (p. 274) (Tellegen \& Atkinson, 1974). Furthermore we outline the main features of the absorption construct, as they were identified by the authors.

1. A heightened sense of reality of the attentional object. The object, either perceived or imagined, grasped in one's attentional focus is experienced as present and real. The authors assumed that an already engaged representational system of the focal object is incompatible with any other reflective consciousness about this primary consciousness content. This could explain the suspension of disbelief such as this is only in my mind.

2. An altered sense of reality in general and of self in particular. Absorbed attention focuses on some facets of reality, emphasizing to a greater extent the experience regarding them, and limiting the awareness of other facets.

3. Imperviousness to normally distracting events. Once an object becomes the focal object, it completely holds the attentional resources, such that it is perceived entirely, in all its details while the individual becomes less distracted by the collateral external events.

4. Cognitive aspects: empathy and cognitive style. Tellegen and Atkinson (1974) considered that absorption is related to empathy and a distinctive cognitive style.

5. The motivational-affective component. Motivationalaffective component is the openness to experience as willingness for object relationship, that permits involvement experience.

Creative Imagination. Imagination seems likely to also affect presence (Heeter, 1992; I auria, 1997). Barber and Wilson (1979) also investigated the personality correlates of hypnotizability. $* * *$ aici corsini $* * *$

The theoretical framework presented above shows that the parallel drawn between hypnosis' findings and presence seems to be justified. Each of the aspects characterizing absorption can also be considered as being applicable to pres- ence. Csikszentmihalyi's (1990) psychology of optimal experience, which seems so close to absorption psychology, already offered an additional insight into the study of presence, since it led to presence as flow experience theory (Draper, Kaber, \& Usher, 1998). Almost all presence theories refer to attention as a significant issue underlying presence. Witmer and Singer (1998) proved that focusing one's attention on a meaningful stimulus set supports one's sense of presence. Draper et al. (1998) proposed an integrative approach to telepresence, featuring a structured attentional resource model, while Kim and Biocca (1997) stressed the role of attention in each of physical, mediated or imaginal space, where the user could become immersed.

Willingness to experience presence. Among the other individual differences which might influence presence, we considered in addition the willingness to experience presence as a form of emotional engagement within the remote world. The role of this factor can be better understood if one looks at it as a prerequisite for willingness to suspend disbelief. Willingness to suspend disbelief was often mentioned in relation to sense of presence. It seems to be a necessary condition for experiencing a high level of sense of presence (I aurel, 1993; Slater \& Usoh, 1993) and ultimately enjoying a mediated experience of any kind (e.g. theater, literature, television, film, VR). Lombard and Ditton (1997) considered willingness to suspend disbelief as a variable likely to induce presence, through weakening the awareness of mediated experience. Users able to stop considering the mediated world as a fake and more willing to accept it as real, would feel a heightened sense of presence. Central to this concept is engagement, which I aurel (1993) described as a primarily emotional state with cognitive components.

Cognitive Style. Cognitive style was also referenced in presence literature as a possibly significant aspect affecting presence (Lombard \& Ditton, 1997; Heeter, 1992). It describes the unique manner in which unconscious mental processes are used in approaching and accomplishing cognitive tasks. **** la scale*** MBTI (Myers \& McCaulley, 1998) measures the strength of one's preference for the way of processing information. MBTI's development is grounded on Jung's theory of personality types (Jung, 1971), the basic dimensions being Extraversion-Introversion, SensingIntuition, Thinking-Feeling and Judging-Perceiving.

Having reflected upon what factors could play an important role in rendering presence, we formulated the following hypotheses. First hypothesis $(\mathrm{H} 1)$ states that creative imagination, absorption, empathy and willingness to experience presence are cognitive factors affecting presence. Second hypothesis (H2) states that among empathy subscales, the fantasy subscale will be the most influential one upon presence. The third hypothesis (H3) states that different dimensions of cognitive style have an impact upon presence. Testing these hypotheses employed designing a study and selecting the scales for measuring each of the previously mentioned factors. The following section presents the sample details, the experimental testbed, the study procedure and the chosen 
Figure 1. Fig.1 Library Room

instruments for measuring absorption, creative imagination and empathy.

\section{Method}

\section{Participants}

The sample consisted of 32 undergraduate and graduate students from the Computer Science Department, 19 males and 13 females, within the age range 20-38. Volunteers were paid for their participation.

\section{Procedure}

The VR system was provided by the ECHOES ${ }^{1}$ system (O'Hare, Sewell, Murphy, \& Delahunty, 2000) a nonimmersive training environment, which addresses the maintenance of complex industrial artifacts. Adopting a physical world metaphor, the ECHOES environment comprises a virtual multi-story building, each one of the levels containing several rooms: conference room, library, lobby etc. Subjects can navigate from level to level using a virtual elevator. $* *$ pics cu rooms***

Since we are interested in subjective factors which determine presence, we considered the desktop VR system a suitable testbed for our study. A distinction should be done between non-immersive and immersive VEs. Whithin immersive VEs most of the users become immersed, despite the intragroup variability based on cognitive factors. We conjecture that in this case, the presence is experienced because of the advanced technological aspects featured by these fully immersive systems. These techniqual issues are so impresive that they simply prevail over the cognitive determinants of presence. On the other hand, whithin nonimmersive VEs whose technological infrastructure is less advanced, the user's experience of presence is mainly due not to system characteristics, but rather to the associated human factors. Being primarily interested in cognitive factors impacting upon presence and grounded on previous assumption we choose Echoes, a desktop VE, as experimental testbed for our study. ***la concluzii $* * *$

After users gained familiarity with the environment and particularly learned movement control, they were asked to perform an exploration task. The exploration task within the virtual building lasts for approximately 20 minutes. In order to induce motivation for an active exploration, and moreover to increase the likelyhood for experiencing presence, a sense of drama was suggested (Laurel, 1993). The instructage was as such: "Imagine that you are following a thief who managed to steal a very valuable painting. He is hiding now inside a multi-storey building, where people are not working yel. Your task is to find the painting a catch the thief. You have only 20 minutes for this action." A color reproduction of the painting accompanied this instruction, together with the following text: "This is the last image of the painting on the museum wall". This scenarious involved user's direct participation, and few of the basic components of I aurel's model: dramatic storytelling, enactement and limited duration of the action (Laurel, 1993).

In order to achieve the objectives and test the hypotheses, we employed both a presence questionnaire and a psychological test battery. The presence operationalization described previously allowed us to build a presence questionnaire, comprising items typical for measurement of presence. The psychological test battery was composed of Tellegen Absorption Scale (TAS), Creative Imagination Scale (CIS), Davis's Interpersonal Reactivity Index (DIRI) and Myers Briggs Type Indicator (MBTI). We will now consider each of these in turn.

***The participants filled in all the questionnaires after the task completion, limiting thus the social threat to sense of presence construct validity (Trochim, 2000). Accordingly this helped reducing the risk of contaminating the users' experience within the virtual world by allowing them to guess the study hypotheses. ***

\section{Tellegen Absorption Scale}

***TAS contains 34 true/false questions; correlates with variables of hypnotizability, imagery, and fantasy proneness (Roche and McConkey, 1990) *** VALIDITY and reliability

\section{Creative Imagination Scale}

Barber and Wilson (1979) devised Creative Imagination Scale (CIS) and proved its correlations with hypnotizability and other measures of imagination and creativity. Creative imagination correlates also with absorption (Crawford, 1982). The scale measures the ability to vividly imagine suggested scenes and situations (e.g. setling of the sun, or the smell of ripe oranges). It involves ten tests in which the subject is inviled to imagine a number of things followed by the assessment of their vividness. ****asks participants to rate the similarity between imagined events and corresponding real events. high scores represent better creative imagery ability*******validity and reliability

\section{Davis's Interpersonal Reactivity Index}

Davis (1994) devised an empathy scale: Davis's Interpersonal Reactivity Index (DIRI) which contains four 7-item

${ }^{1}$ ECHOES (European Project Number MM1006) is partially founded by the Information Technologies, Telematics Application and I eonardo da Vinci programmes in the framework of Educational Multimedia Task Forec. 
subscales, each measuring a separate facet of empathy. Fantasy subscale (FS) measures the tendency to imaginatively transpose oneself into fictional situations. The perspective taking subscale measures the reported tendency to spontaneously adopt the psychological point of view of others in everyday life. Empathic concern assesses the tendency to experience feeling of sympathy and compassion for unfortunate others, while personal distress taps the tendency to experience distress and discomfort in response to extreme distress in others.

We were particularly interested in identifying the correlation between FS and presence, since the ability to imaginatively transpose oneself into fictional situations could be considered a prerequisite for transposing oneself into a virtual world.

\section{Willingness to experience presence}

We measured this variable through an item within the presence questionnaire: "to what extent were you willing to be transported in the virtual world". *** gresit - cu o intrebare dupa experiment

\section{Myers-Briggs Type Indicator}

MBTI (Myers \& McCaulley, 1998) measures the strength of one's preference for the way of processing information. MBTI's development is grounded on Jung's theory of personality types (Jung, 1971), the basic dimensions being Extraversion-Introversion, Sensing-Intuition, ThinkingFeeling and Judging-Perceiving.

\section{Results}

\section{Item Analysis}

The presence questionnaire contained 34 items measured on a 7 -point I.ikert scale. Item total-correlation analysis allowed us to identify the variables that are not internally consistent with the questionnaire. Using the criterion of 0.33 as the cut-off point, 11 items were deleted, the resultant questionnaire containing 23 items. Table 2 presents the mean, median and standard deviation of scores along presence dimensions and variables.

\section{Reliability and Validity}

The Cronbach's alpha coefficient is $\alpha=0.92$ while the correlation with presence counter questionnaire devised by Slater and Steed (2000) is significant: $r(30)=.84, p<0.01$. Consequently, our questionnaire leads to measurements both reliable and valid.

\section{Presence and Cognitive Factors - Correlational Approach}

Pearson's correlations were run between presence, as an overall score of our questionnaire and scores of each of the previously mentioned cognitive factors. As shown in the
Table 2

Mean, Median and Stand. Dev. for Each Presence Variable

\begin{tabular}{lllll}
\hline Dimens. & Variables & Mean & Med. & SD \\
\hline \multirow{4}{*}{ Being } & Perceiving & 3.42 & 3.50 & 1.19 \\
there & Self-perceiving & 3.43 & 3.33 & 1.29 \\
& Imagination & 3.87 & 4.00 & 1.58 \\
& Acting there & 4.07 & 4.00 & 0.81 \\
& Altentional res. & 5.26 & 5.00 & 0.90 \\
& Willingness & 4.00 & 4.00 & 1.66 \\
\hline \multirow{2}{*}{ Not being } & Not perceiving & 3.38 & 3.50 & 1.25 \\
here & Self perception & 2.68 & 2.00 & 1.37 \\
& Not recalling & 3.46 & 3.50 & 1.70 \\
& Not acting here & 4.34 & 4.00 & 1.45 \\
Reflective & Returning exper. & 3.21 & 3.00 & 1.60 \\
\hline consc. & Awareness of oneself & 3.33 & 3.37 & 1.05 \\
& Awareness of outside & 3.40 & 3.00 & 1.24 \\
\hline
\end{tabular}

second column of Table 3, all the correlation coefficients were statistically significant, indicating strong positive relationships between presence and the variables considered. A detailed analysis revealed that among the four dimensions captured by the empathy subscales, fantasy subscale has the strongest impact upon presence. This result comes to validate $\mathrm{H} 2$. Strong positive correlations (third column of Table 3) were also found between each of these factors and presence measured by presence questionnaire devised by Slater and Steed (2000). However, the strongest correlation was found between presence and willingness to experience presence.

Table 3

Correlation Coefficients Between Presence and Cognitive Factors

\begin{tabular}{lll}
\hline Variables & $\begin{array}{l}\text { Presence } \\
\text { Questionnaire }\end{array}$ & $\begin{array}{l}\text { Presence Counter } \\
\text { Questionnaire }\end{array}$ \\
\hline Creative Imagination & $.38, p<.05$ & $.18, p<.31$ \\
Absorption & $.42, p<.01$ & $.35, p<.05$ \\
Empathy & $.48, p<.01$ & $.46, p<.01$ \\
Fantasy Subscale & $.46, p<.01$ & $.35, p<.05$ \\
Willingness & $.58, p<.01$ & $.41, p<.05$ \\
\hline
\end{tabular}

\section{Presence and Cognitive Factors - Quasi- Experimental Approach}

Correlation states a relationship between presence and the investigated variables but it does not imply any causation. However, we are interested in testing cause-effect relationships. Since the cognitive factors are variables that cannot be manipulated, our study is a quasi-experimental one, where participants were assigned to a particular condition because they already qualified for it. In order to test the impact of those variables considered upon presence we run ttests, comparing the level of sense of presence experienced 
by groups of users, identified on the basis of their scores for cognitive factors. Thus we considered two independent groups for each factor, with the cutting-off point to the 50th percentile for creative imagination, willingness to experience presence, empathy, fantasy subscale and 66th percentile for absorption (Group 1 is above cutting point, while Group 2 is below it). As shown in Table 4, the differences were significant at the level .05 and showed that persons who are highly absorbed, more creative, more empathic or more willing to get immersed do experience a greater level of sense of presence.

Table 4

T-Tests Comparing Presence Experienced by Users Grouped by Their Cognitive Factor Scores

\begin{tabular}{lllcc}
\hline $\begin{array}{l}\text { Variables } \\
(\mathrm{N}=32)\end{array}$ & $\begin{array}{l}\text { Group 1 } \\
\text { High }\end{array}$ & $\begin{array}{l}\text { Group 2 } \\
\text { Low }\end{array}$ & $\begin{array}{l}\text { Presence } \\
\text { Score }\end{array}$ \\
\hline & Mean $(S D)$ & Mean $(S D)$ & $t-$ Test & $r_{p b}^{2}$ \\
\hline Creative Im. & $114.4(21.9)$ & $96.7(16.5)$ & $2.5, p<.05$ & .18 \\
Absorption & $117.0(21.5)$ & $101(19.3)$ & $2.1, p<.05$ & .13 \\
Empathy & $113.9(22.3)$ & $99.2(18.2)$ & $2.0, p<.05$ & .12 \\
Fantasy & $117.8(21.9)$ & $99.1(17.9)$ & $2.6, p<.05$ & .18 \\
Willingness & $115.2(20.5)$ & $92.7(14.6)$ & $3.4, p<.01$ & .27
\end{tabular}

We also found that participants more willing to be transported in the virtual world are significantly more absorbed $t(30)=2.74, p<.01, r_{p b}^{2}=.20$, more empathic $t(30)=$ $2.49, p<.05, r_{p h}^{2}=.17$, and more imaginative $t(30)=$ $2.10, p<.05, r_{p b}^{2}=.13$.

\section{Multiple Regression Analysis}

Multiple regression analysis, a method that can be used to study the effects of several independent variables on one dependent variable, is employed to evaluate the global influence of previously discussed cognitive factors on sense of presence (Table 5). Because of the high correlation between creative imagination and absorption $r(30)=.56, p<.001$, these two dimensions cannot be seen as independent predictors in the regression equation. As we have seen already, creative imagination and absorption are overlapping concepts, a fact indicated by their theoretical foundations and experimental studies carried out in the area of hypnosis (Crawford, 1982). Thus we computed a composite predictor variable as an average of these two lactors.

Results indicate that in combination, all three factors significantly predict the user's sense of presence, with willingness to experience presence making the largest individual contribution. The other significant contribution is made by creative imagination \& absorption factor, while fantasy subscale score seems not to be significant. The sample multiple correlation coefficient, namely the correlation between the
Table 5

Regression Analysis Summary for Variables Predicting Sense of Presence

\begin{tabular}{ll}
\hline Variables & Presence \\
\hline & Beta \\
Creative Imagination \& Absorption & $.296, p<.050$ \\
Empathy - Fantasy Subscale & $.139, p<.369$ \\
Willingness to experience presence & $.541, p<.001$ \\
$R^{2}=.568 d f=3.27 F=11.85 . p<.001$ &
\end{tabular}

actual sense of presence and the predicted sense of presence was $r(30)=.75, p<.001$. About $52 \%$ of the variance of the sense of presence in the sample can be accounted for by willingness to experience presence and the creative imagination $\&$ absorption.

\section{Presence and Cognitive Style}

The results regarding sense of presence and cognitive style are still ambiguous, since no significant correlation emerged. The highest correlation was found between Presence and Feeling. On the continum Thinking-Feeling, Feeling individuals seem to be more empathic $r(30)=.52, p<0.01$, more creative $r(30)=.52, p<0.01$ and more absorbed $r(30)=.39, p<0.05$.

\section{Discussion}

In this paper we have investigated presence. In order to carry out a subjective measurement of presence, adequate to both the system and tasks characteristics, we defined and operationalized the presence concept, and subsequently developed a presence questionnaire. It was shown that there are grounds for taking questionnaire's measurements as both reliable and valid.

At the heart of the presence lie the concepts of emotion, attention and imagination. The more cognitive resources are deployed, the more immersed the user becomes. The experience within the remote world is a complete one, encompassing cognitive, emotional and behavioral aspects. In other words, the more the users think, feel and act in the remote world and the more collateral activities are inhibited within the real worlds, the more sense of presence they will experience.

The second objective consists of identifying cognitive factors underlying presence. An analysis of the presence literature accompanied by an insightful approach of hypnosis psychology lead us to the factors of absorption, creative imagination, empathy, willingness to experience presence and cognitive style. Results indicate that creative imagination, absorption, empathy, especially fantasy subscale and willingness to experience presence play distinctive roles in the experience of presence, validating $\mathrm{H} 1$ and $\mathrm{H} 2$. Significant positive correlations between each of these factors and presence, indicate that the more willing to experience presence, the more empathic, the more absorbed, or the more imaginative 
the users are, the more sense of presence they will experience.

In addition to investigating the way in which these factors correlate with presence, we were also interested in identifying possible cause-effect relationships. Thus t-tests confirmed significant differences in the level of presence experienced by groups of users. Participants were assigned to groups on the basis of their scores for the cognitive factors. Findings indicate that participants scoring above the median for creative imagination, willingness to experience presence, empathy, FS and above 66th percentile for absorption, experienced a significantly higher level of sense of presence. Study results summarized here confirm previously hypothesized impact of these cognitive factors upon presence, as presence literature highlighted them (Lombard \& Ditton, 1997; Lombard, 2002; Heeter, 1992; I auria, 1997; Slater \& Usoh, 1993).

The third objective not only focuses on the singular relationships between presence and each of its cognitive factors, but it also aims to predict presence based on these factors. The multiple linear regression equation presents each variable measured in $\mathrm{Z}$. score, while factor $\mathrm{K}$ replaces symbolically important aspect which have been omitted by us.

Predicted presence $=(.54) x$ Willingness to experience presence $+(.30) x$ Creative Imagination \& Absorption $+K$

An interesting aspect is that together these factors cover more than half of the variance in the sense of presence. This is an important result which should nourish the presence research toward more empirical investigations of the role of individual differences upon presence. Results indicate that willingness to experience presence is the most important cognitive factor among those investigated by us, in predicting user's sense of presence. This issue is remarkable and therefore discussed in detail.

We don't know if individuals feel more presence because they are more willing to or they are more willing because of their particular configuration of cognitive factors determinant for experiencing presence. Results show that participants more willing to experience presence, are better equipped in terms of cognitive factors, but the variance in presence explained by them is not so high. The attitude or mood of approaching the VR experience carries a specific impact. It is more likely that the cognitive factors investigated are latent and it is the explicit desire to feel presence that acts as a catalyst for them. Thus, even if the willingness to experience presence might be increased by the innate cognitive factors, it is however the most addressable factor. It is a challenge for virtual environment designers to create, and nourish this desire, in order to increase the level of presence and possibly enhance users' performance. The special preparation of users before they actually experience the VR could increase the willingness to feel presence.

Our findings bridge an empirical gap related to the impact of individual differences upon sense of presence. They support the relationships between user's characteristics and presence as presence literature hypothesized. They also show that the impact carried out by these factors is sufficient to motivate a closer examination by both the presence research community and virtual environment designers. It seems that presence proved again to be a multiply determined construct, and the challenge to discover the distinct impact of each determinant is still unresolved. Therefore more empirical evidence is required in order to highlight the complex internal equation which enables one to feel presence.

Ultimately, the role of studying individual differences comes under the remit of user centered design. Once we understand the individual differences in terms of users' abilities to capture, process and make use of VR systems, the next slep would be to design them to accommodate these differences (Kaber et al., 2002). Given the potential relationship between presence and task performance, identifying appropriate VR design methods to optimize presence is important. Effectiveness of these designs could be increased by users' segmentation along the dimensions which derive the greatest impact upon presence and performance. To what extent these cognitive factors are addressable remains an open question. An approach considering not only human or technological factors but also media content could provide answers (Kim \& Biocca, 1997).

This research constitutes a case study for which the results are merely preliminary. The findings indicate that tools developed for studying personality correlates to hypnozability can be successfully applied in the study of presence. To date we have only identified the work of Tromp (1995), where the hypnosis results were also theoretically exploited in investigating presence.

Study limitation consists in the non-random sampling procedure for selecting participants, a fact which inhibits the power of generalizing results upon other similar contexts. Due to the limited sample size and the broad dispersion of the results along the dimensions of cognitive style, $\mathrm{H} 3$ remains promising but as yet unproven. Future work should be conducted in order to prove its validity. Since the tasks undertaken within the virtual world were solitary individual tasks, future work will examine and consider collaborative tasks undertaken in the ECHOFS Collaborative Virtual Environment offering insights into impact of cognitive factors upon social presence.

\section{References}

Barber, T., \& Wilson, S. (1979). The Barber suggestibility scale and the creative imagination scale: Experimental and clinical applications. The American Journal of Clinical Hypnosis, 2l(2-3), 84-108.

Crawford, H. (1982). Hypnotizability, daydreaming styles, imagery vividness and absorption: A multidimensi onal study. Journal of Personality and Social Psychology, 42(5), 915-926.

Csikszentmihalyi, M. (1990). The psychology of optimal experience. Harper and Row.

Davis, M. (1994). Empathy: A social psychological approach. Oxford: Westview Press.

Draper, J., Kaber, D., \& Usher, J. (1998). Telepresence. Human Factors, 40(3), 354-375.

Farthing, W. (1992). The psychology of consciousness. PrenticeHall, Ine. 
Gerrig, R. (1993). Experiencing narrative worlds. on the psychological activities of reading. New Haven, CI: Yale University Press.

Heeter, C. (1992). Bcing there: The subjective experience of presence. Presence: Teleoperators and Virtual Environments, 1(2), 262-271.

Heinlein, R. (1950). Waldo and magic. New York: Del Rey.

Jung, C. (1971). Psychological types. In L. Ress \& W. McGuire (Eds.), The collected works of c.g.jung (Vol. 6). Princeton University Press.

Kaber, D., Draper, J., \& Usher, J. (2002). Influence of individual differences on VR application design for individual and collaborative immersive virtual environments. In K. Stanney (Ed.), Virtual environments handbook. I awrence Hrlbaum.

Kim, T., \& Biocca, F. (1997). Telepresence via television: Two dimensions of telepresence may have different connections to memory and persuasion. Journal of Computer-Mediated Communication, 3(2).

I aurel, B. (1993). Computers as theatre. Addison -Wesley Publishing Company.

Lauria, R. (1997). Virtual reality: An cmpirical-metaphysical testbed. Journal of Computer-Mediated Communication, 3(2).

Lauria, R. (Nov. 2000). Presence-listserv. re: "presence" and media.

Lessiter, J., Keogh, J., \& Davidoff, J. (2000). A cross-media prescnce questionnaire: The itc sense of presence inventory. Presence: Teleoperators and Virtual Environments, $10(3), 282-297$.

Lombard, M. (2002). Resources for the study of presence: Presence explication. Retricved March 15, 2002 from the WWW: http://www.temple.edu/mmc/ispr/explicat.htm.

Lombard, M., \& Ditton, T. (1997). At the heart of it all: The concept of presence. Joumal of Computer-Mediated Communication, $3(2)$.

Loomis, J. (1992). Distal attribution and presence. Presence: Teleoperators and Virtual Environments, /(1),113-118.

Minsky, M. (1980). Telepresence. Omni.

Myers, I., \& McCaulley, M. (1998). Manual: A guide to the development and use of the MBTI. Consulting Psychologist Press.

O'Hare, G., Sewell, K., Murphy, A., \& Delahunty, T. (2000). An immerse training experience. In (pp. 179-188). P. Brusilovsky, O. Stock and C. Strapparava (Eds.), Lecture Notes in Computer Science 1892, Springer-Verlag.

Psotka, J., \& Davison, S. (1994). Cognitive factors associated with immersion in virtual cnvironments. In Proceedings of the conference on intelligent computer-aided training and virtual environment technology.

Quarrick, G. (1989). Our sweetest hours: Recreation and the mental state of absorption. Jefferson: McFarland.

Revonsuo, A. (1996). Virtual reality as a metaphor of consciousness. In Proceeding of conference toward a science of consciousness.

Schloerb, D., \& Shcridan, T. (1995). Experimental investigation of the relationship between subjective telepresence and performance in hand-eye tasks. Telemanipulator and Telepresence Technologies.

Sheridan, T. (1992). Musings on telepresence and virtual presence. Presence: Teleoperators and Virtual Environments, l(1), 120126.

Slater, M., \& Steed, A. (2000). A virtual presence counter. Presence: Teleoperators and Virtual Environments, 9(5), 413-434.
Slater, M., \& Usoh, M. (1993). Representations systems, perceptual position, and presence in immersive virtual environments. Presence: Teleoperators and Virtual Environments, 2(3), 221-233.

Tellegen, A. (1981). Practicing the two disciplines of relaxation and enlightenment: Comment on "Role of the feedback signal in electromyography biofecdback: the relevance of attention" by Qualls and Sheehan. Journal of Experimental Psychology: General, 110 .

Tellegen, A. (1982). Brief manual for the differential personality questionnaire. (Unpublished manuscript. University of Minnesota, Department of Psychology, Minncapolis)

Tellegen, A., \& Atkinson, G. (1974). Openness to absorbing and self-altering experiences ("Absorption"), a trait related to hypnotic susceptibility. Journal of Abnormal Psychology, 83.

Trochim, W. (2000). The research methods knowledge base. Internet WWW page, at URL: ihttp://rochim.human.cornell.edu/kb/index.htm $;$ (version current as of August $(02,2000)$ ).

Tromp, J. (1995). Presence, telepresence and immersion: The cognitive factors of embodiment and interaction in virtual environments. In Proceedings of immersive virtual environments.

Witmer, B., \& Singer, M. (1998). Measuring presence in virtual environments: A presence questionnaire. Presence: Teleoperators and Virtual Environments, 7(3), 225-240. 